\title{
Computer Neuropsychological Training in Mentally Retarded Children
}

\author{
Enrico Castelli, Geraldina Poggi, Cristina Ferraroli, Vittoria Trebeschi \\ Scientific Institute Eugenio Medea \\ Basisio Parini, Como . Italy
}

\begin{abstract}
Informatic tecnology can be the right answer to deal with some neuropsychological troubles of children. The goal of this study is the application of computer programs as a possible strategy in rehabilitation of children with cognitive problems. Four programs were selected to stimulate various basic brain functions: problem solving, categorization, logical sequence and spatial thought. The programs were tested on a group of 20 mentally retarded young subjects matched with a comparison group of 20 like subjects trained with ordinary techniques. The computer trained group showed a significant improvement in tests involving attention, motivation for learning and problem solving abilities. These results, in our opinion, would confirm the usefulness of specific software as a rehabilitative method in dealing with cognitive problems of children.
\end{abstract}

\section{Introduction}

In the last years personal computer has been used as a major tool for the traitment of many kinds of disabilities, including the cognitive disorders $(1,3,6,8,9)$.

The aim is, in the latter case, at stimulating the residual abilities of the disabled subjetcs in order to exploit such competencies at the best or (if the patients are children) at furthering their development $(1,2,6)$.

Even though the literature on this topic is quite rich, the researches specifically directed to the problem of mentally retarded children are very few: surprisingly, because the mentally retarded possibly could take great advantages from this kind of rehabilitation.

As our Institute is dealing, for many decades, with the problems of mental retardation and learning disabilities, we are researching even in this field: a recent study, still in advancing, is summarized as follows.

\section{Rationale}

Some different programs (software) have been selected in order to stimulate specific intellectual functions as sequencing, selecting among multiple choices, classifying and performing spatial tasks $(1,2,4,5,7)$. 
The real goal is the increasing of the child's abilities in using particular information-processing strategies through a number of facilities which enable him or her to perform a task.

The hypothesis was that a goal-oriented training would allow these subjects to reach higher performances, if compared with those of a control-group treated with the traditional, not computerized, rehabilitative techniques.

It is worth noting that we emphasize rather the concept of strategy than the issue of the neuropsychological competency. We will see that even motivation has its own weight.

\section{Materials and Methods}

Four programs were selected suited to a MS-DOS based personal computer; this choice was justified by the low cost of this machine and its large diffusion.

The first program, Sequence, requests the correct rearrangement of a succession of images. It displays four pictures, each representing one step of a logical sequence, in a random order. The child has to arrange the sequence, pointing to each picture in the right order. The program gives feedback by playing an animation that confirms the passage leading from one step to the next.

The second program, Matrix, requests logical selection from a group of objects. It displays in the left side of the screen an object and in the right side a set of pictures. The child has to choose the picture among those displayed in the set that logically matches the right image. Acoustic and visual feedback are given.

The third program, Claxi, stimulates the children's ability to classify plane figures following different criteria.It displays in the left top comer of the screen fifteen figures, with a maximum of three different colours, shapes and sizes. In the half bottom corner of the screen there are three empty boxes. The child has to draw one figure at a time in one of the three boxes, according to a given classification criterion. Feedback is given following the criterion which has been used by the child himself, not to discourage him.

The fourth program, Views, stimulates spatial thought, requiring the correct matching between two different points of view: downwards and forward. It is actually based on a well known Piaget's test. It display the surface of an island on whose coasts are various landmarks (e.g. some trees, a train, a city etc.). A sailboat appears in the sea surrounding the island. The frontal view of each landmark appearing on the island (as it can be seen from the current sailboat position) is displayed inside a bottom-screen frame. The program can either change the frame of the content, asking the child to move the sailboat where such a view is possible, and the content itself that represents the view from the boat. Visual feedback is given.

These programs were tested on 40 selected children, ranging in age from 6 to 14 years ( $10 \mathrm{y} .7 \mathrm{~m} . \pm 2 y .10 \mathrm{~m}$ ), suffering from learning disabilities as a consequence of inferential and logical impairment (depending on a condition of mental retardation), free from sensory disorders or severe emotional problems. We selected only children with Total Intelligence Quotient (TIO) at the Wechsler Scale (WISC-R) ranging from 50 to 80 . 
All the subjects underwent psychometric tests in order to assess aftention level, learning motivation and problem solving abilities. We used also ordinal scales: Raven's Standard/Coloured Progressive Matrices (PM) test - for the assessment of inferential and logical abilities - was administered.

The 40 children were then randomly divided into two groups of 20 subjects, matching for age and TIQ. The subjects belonging to the first group attended 50 training session, 45 minutes each, twice a week, using the selected programs; the subjects of the second group attended 50 training session, 45 minutes each, twice a week, using ordinary techniques (handy training equipment). At the end of the period all the subiects were re-tested with the same battery of tests.

\section{Results}

The psychometric tests undertaken by the children before and after rehabilitation showed a statistically significant increase (sign - test, $p<0.05$ ) of the attention level at the end of the training in the computer trained group ( 6 positive differences, 14 ties) compared with the not significant increase in the control group (2positive difference, 18 ties) (fig. 1). In a similar way, motivation for learning significantly increased $(p<0.05)$ in the computer treated group (8 positive difference, 12 ties) and did not significantly change in the control group (1 positive difference) (fig. 2). Problem solving abilities increased in both of the groups, but the difference was statistically significant $(p<0.05)$ only in the computer treated group ( 7 positive difference, 13 ties vs 3 positive difference, 17 ties in the control group) (fig. 3).

Results in the PM test did not show any statistically significant change in the computer trained group $(85.6 \pm 15.6)$ before rehabilitation (b.r.); $87.9 \pm 15.6$ and after rehabilitation (a.r).

The change in the control group was larger $(82.8 \pm 30.2$ b.r, $89.3 \pm 3.3$ a.r) even though a statistically not significant. A t-test comparison between the PM scores of the computer trained group and of the control group before and after rehabilitation was not significant.

\section{Discussion}

From the outcomes of our study, it seems that the use of specific softwares in training retarded children is more effective if compared with that based on the traditional ordinary techniques.

Undoubtedly the weight of motivation must be considered: working with the computer may be playful and fun and possibly promotes the children's interest.

Yet the improvement of attention and problem-solving capacities has been proved: it is quite unlikely to consider such an improvement the mere effect of a higher interest.

Possibly interacting and working with the PC compels the retarded child to deal with algorythms, to build mental representations, to process analysis/synthesis tasks and consequently to become more proficient in using strategies that the PC can facilitate. 
So the better performances by the computer-trained subjects in the problem-solving tests can be easily (but not completely) explained.

Indeed extensive work still has to be done both in order to understand the actual processes underlying the outcomes and to create a wider range of programs.

We also believe that it is necessary to find new procedures enabling the children to train themselves, actually using the PC as an inanimate but powerful therapist.

\section{References}

1) Castellan .N.J.(1993) Evaluating information technology in teaching and learning Behavior Research Methods, Instruments \& Computers 44, 6

2) Castelli. E. , Piccinelli P. , Borgatti R. , Reni G. , Moretti M ,(1991) Facilitazioni informatiche per lo sviluppo di competenze neuropsicologiche nel grave disabile motorio. Saggi Anno XVII, 1,31-36

3) Corradini E. ,Tressoldi PE . „Pellegrini A, Ciot C., (1993) L'analisi del software educativo finalizzata ad una programmazione riabilitativa mirata. Edizioni La Nastra Famiglia

4) Fedrizzi E. , DalBrun A , Rivala A., Schiaffino A. Fronticelli G. Castelli E., Belloni G . (1993 )Indicazioni e limiti alli̧sg del personal computer per il grave tetraplegico in età scolare. Giornale di Neșropsichiatria dell'età evolutiva. $13,2,129-140$

5) Ferlazzo F. , Conte S. , Gentilomo A. , (1993) Event - Related Potentials and recognition memory : the effect of word imagery value. International Joumal of Psychophysiology 15, 115-122.

6) Merteus D. M. et al (1992) Combining Cognitive learning theory and computer assisted instruction deaf learners . American Annals of the Deaf. 137, 399 - 403

7) Ross.F. L. (1992) The use of Computers in Occupational Therapy for Visual Scanning training. American Joumal of Occupational Therapy 46, 314 -322

8) Skinner A .D. , Trachtman L.H.(1985) Use of a computer program in cognitive rehabilitation . American Journal of Occupational Therapy., $39,7,470-472$.

9) Weiss.P.(1990) The integration of Computers into the occupational Therapy Department . American Journal of Occupational Therapy . 44, 6, 527-534. 
FIGURE I

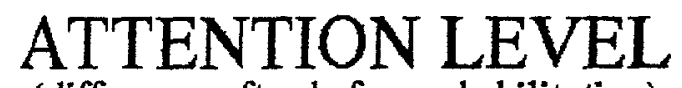

(difference after-before rehabilitation)

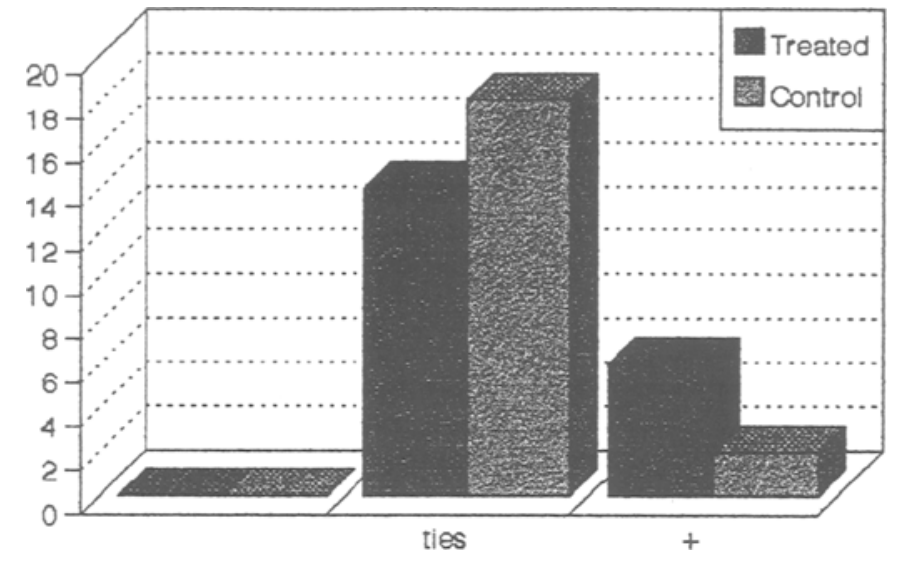

FIGURE 2

\section{MOTIVATION FOR LEARNING}

(difference after-before rehabilitation)

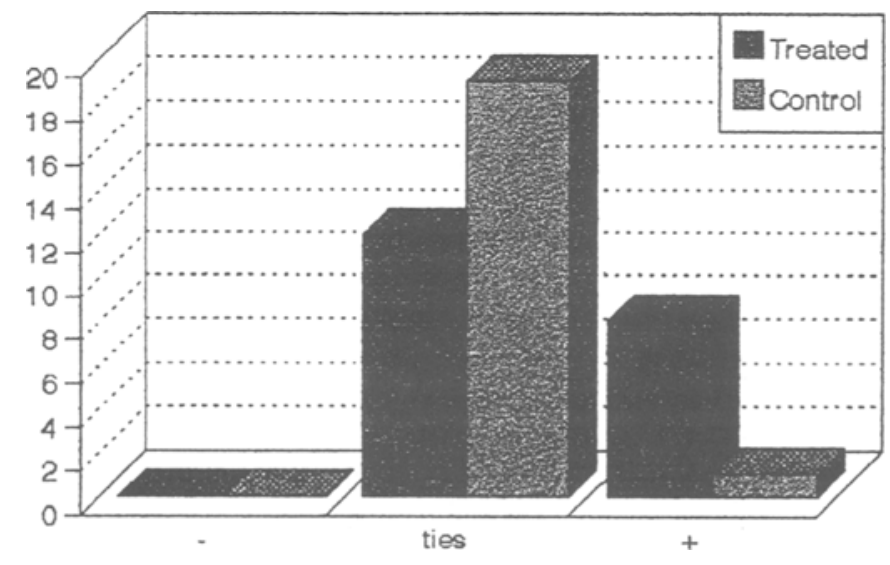


F I GURE 3

PROBLEM SOLVING ABILITIES

(difference after-before rehabilitation)

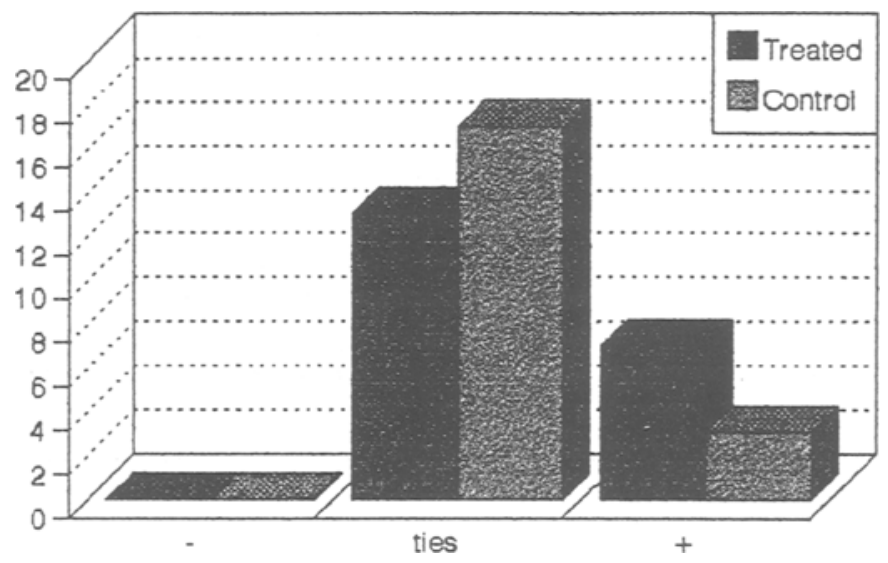

